\title{
Computational Model of Greenhouse Gases Emissions in Iron and Steel Industry and Its Application
}

\author{
Ying LIU*, Meng DUAN and Yun-jie ZHAO
}

\author{
School of Civil Engineering and Architecture, Anhui University of Technology, 59 Hudong Road, \\ Maanshan 243002, PR China \\ E-mail: liuying9@ahut.edu.cn
}

\begin{abstract}
Keywords: GHGs, enterprise model; process model; carbon emissions; integrated iron and steel enterprise

Abstract. Under the guidance of international standards for carbon emissions, two greenhouse gases (GHGs) accounting models have been established for integrated iron and steel enterprises. One is the enterprise, and the other is the process as a whole boundary, so they are named the enterprise model and the process model respectively. The enterprise model obtains the carbon emissions through the balance of carbon input and output of the enterprise boundary. The process model obtains the carbon emissions through the balance of carbon input and output of the process boundary under the condition of considering the enterprise inner circulation. A case study using the two models was also made in an integrated iron and steel enterprise. Results show that the enterprise's main carbon emissions are from fuel combustion. Thus, reducing fuel consumption is of great significance to the steel industry in the aspect of energy conservation and emissions reduction. The enterprise model can account for enterprise's overall carbon emission and can be applied to government appraisal of the enterprise's carbon emissions. The process model can not only check out process emissions, but also effectively quantifies enterprise internal material flow, energy flow and by-product circulation effects on carbon emissions. It can also provide the basis for internal carbon emission assessment mechanism within an enterprise.
\end{abstract}

\section{Introduction}

Greenhouse gases (GHGs), in particular, increasing carbon dioxide $\left(\mathrm{CO}_{2}\right)$ in the atmosphere, cause global warming which in turn has become a main cause of global climate change. Climate scientists have observed that $\mathrm{CO}_{2}$ concentrations in the atmosphere have been increasing significantly over the past century, compared to the pre-industrial era (about 280 parts per million, or ppm). The 2014 concentration of $\mathrm{CO}_{2}(397 \mathrm{ppm})$ was about $40 \%$ higher than in the mid-1800s, with an average growth of $2 \mathrm{ppm} / \mathrm{year}$ in the last ten years. The Fifth Assessment Report from the Intergovernmental Panel on Climate Change (Working Group I) states that human influence on the climate system is clear ${ }^{[1]}$. Among the many human activities that produce greenhouse gases, the use of energy represents by far the largest source of emissions. Within the energy sector, $\mathrm{CO}_{2}$ resulting from the oxidation of carbon in fuels during combustion dominates total GHG emissions.

In 2013, the global $\mathrm{CO}_{2}$ emissions reached $32.2 \mathrm{Gt}$, an increase of $2.2 \%$ over 2012 level . China $\mathrm{CO}_{2}$ emissions were $8.9 \mathrm{Gt}$, accounted for $28 \%$ of the total emissions ${ }^{[2]}$ with the iron and steel industry as the main source of $\mathrm{CO}_{2}$ emissions. In the domestic Chinese iron and steel industries accounted for $9.76 \%$ of the whole country's coal $\mathrm{CO}_{2}$ emissions ${ }^{[3]}$. At present, the international organization for GHGs accounting standards relies mainly on the 2006 IPCC national greenhouse gas inventories guide written by the Intergovernmental Panel on Climate Change 
(IPCC). It is used to calculate the various industrial direct emissions of GHGs within national scope ${ }^{[4]}$. The World Resources Institute (WRI) and the World Business Council for Sustainable Development (WBCSD) jointly prepared to release the GHGs accounting system (GHG Protocol), while the International Organization for Standardization (ISO) released the ISO14064 series standard, PAS2050:2008, and the goods and services in life cycle of greenhouse gas emissions evaluation standard was formulated by the British Standards Institution (BSI) (British Standards Institution (BSI, 2008) and so on ${ }^{[5]}$. GHGs accounting methods which are suitable for enterprises have A Corporate Accounting and Reporting Standard in the GHG Protocol and Greenhouse gasesPart1: Specification with guidance at the organization level for quantification and reporting of greenhouse gas emission and removal in the ISO14064 series standards ${ }^{[6]}$.

GHGs accounting methods which can be applied to the iron and steel industry/enterprise mainly have the IPCC national greenhouse gas inventories, WRI\&WBCSD joint development of steel industry emissions calculation tools ${ }^{[7-8]}$. While the world steel association (WSA) puts forward calculation methods of the CO2 emissions: the first ${ }^{[9]}$ and second edition ${ }^{[10]}$, the IPCC method can only account for iron and steel industry direct emissions, and the other two methods both can account for the direct and indirect emissions. In addition, only WRI\&WBCSD puts forward the concept of Scope. At present, some international large-scale iron and steel enterprises issued a response to carbon emissions and climate change studies. For example, South Korea's Posco Co Ltd issued its first Carbon Reporting in 2009 ${ }^{[11]}$. The report details the Posco work in coping with climate change and plans to reduce the existing per ton $\mathrm{CO}_{2}$ intensity by $9 \%$ by 2020 . Nippon Steel also attaches great importance to environmental protection, and is actively working to expand the global technology research and development cooperation to reduce $\mathrm{CO}_{2}$ emissions. In 2008 these decreased by $15.1 \%$ compared to $\mathrm{CO}_{2}$ emissions in 1990 (Nippon Steel, 2008). Chinese Baosteel released the entire annual social responsibility report for the first time in $2008{ }^{[12]}$. In the environmental section of the report, it introduced its work and achievement in the circular economy, ecological restoration and environmental monitoring and so on, but there was no mention of enterprise carbon emissions and specific targets.

In summary, the greenhouse gas accounting standards have been more comprehensive, but the lack of carbon dioxide emissions accounting model and the software under the standard framework, lead to enterprise difficult to prepare carbon reporting, existing model is the black box model for enterprise boundary, can not reveal the flow of enterprise internal $\mathrm{CO}_{2}$ conditions, at the same time, the assessment mechanism of $\mathrm{CO}_{2}$ emissions in the enterprises has not yet formed. In order to solve this problem, convert the standard into applicable calculation method on the basis of read relevant greenhouse gas accounting standard, set up the accounting model of $\mathrm{CO}_{2}$ base on process, which can effectively promote enterprise to release the carbon report process. This paper provide research tool for iron and steel industry preparing list of carbon emissions and studying emissions reduction decision, and also provide a baseline for the assessment mechanism of $\mathrm{CO}_{2}$ emissions in the enterprises, at the same time, also can provide reference for other industries in the aspect of carbon emissions accounting.

\section{Enterprise Model of Integrated Iron and Steel Enterprises}

Under the guidance of international standards for carbon emissions combined with the characteristics of integrated iron and steel enterprises, there are two representative $\mathrm{CO}_{2}$ greenhouse gas calculation models. One is the enterprise model, while the other is the whole process boundary model. Hence they are named the enterprise model and the process model respectively. The aim of this study was to account for the production phase of carbon emissions. As a result it ignores some carbon emissions inventories, such as fixed assets, waste disposal, commuting and travel, lease assets, investment, sold products in transportation, processing, use and final disposal, franchisees, suppliers, and other enterprises' external activities. 
2.1. Classification of Carbon Emissions Inventory. Using A Corporate Accounting and Reporting Standard in the GHG Protocol as a reference, the accounting model takes the integrated iron and steel enterprises as the whole boundary, divided into three operational boundaries ${ }^{[13]}$. These are: scope 1, scope 2, and scope 3 where Scope 1 refers to the carbon emissions from the carbon sources that are owned or controlled by the enterprise organization, including emissions from fuel combustion and process; Scope 2 refers to the carbon emissions from electricity, steam and other power consumption that the enterprise purchased; and Scope 3 refers to the carbon emissions caused by the activities of the enterprises, where the carbon sources are owned or controlled by other organizations, including the emissions from upstream and transportation of the materials, energy and carbon content of output products. Through the determined operational boundaries and classified carbon sources, the model can effectively account for enterprise carbon emissions of each scope and carbon source, discern their distribution ratio in the factory, and then provide a basis to reduce emissions for the iron and steel enterprises.

Carbon emissions calculations are made according to the principle of carbon balance, where the balance of $\mathrm{CO}_{2}$ inputs and outputs of the system are used to calculate the $\mathrm{CO}_{2}$ emissions ${ }^{[14]}$.

The classification of inputs and outputs for the enterprise model's carbon sources is shown in figure 1 .

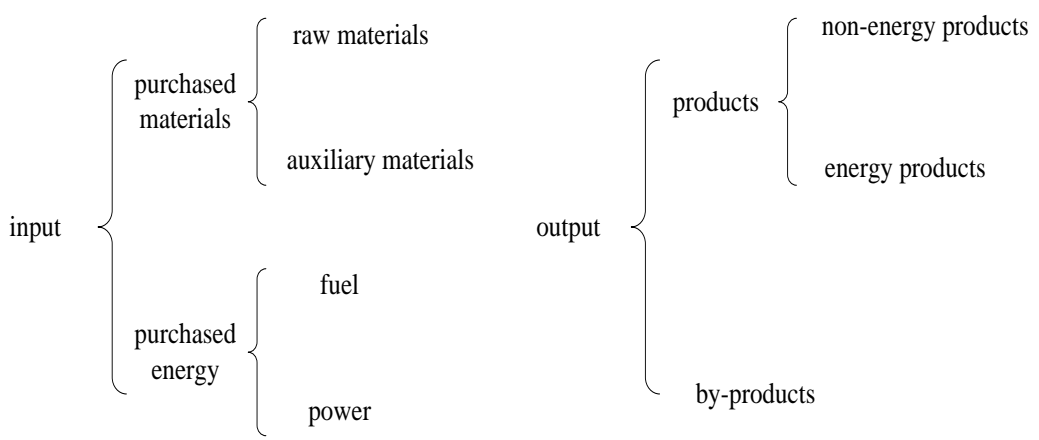

Figure 1. Input and output for the enterprise model's carbon source.

Enterprise input purchases are classified as materials and energy with materials sub-classified as raw materials (primary) and auxiliary materials (secondary), and purchased energy divided between fuel and power based on carbon. Output, is classified between products and by-products, where products refer to the functional products of the production process in iron and steel enterprises and by-products for non-functional products, such as the molten iron product from blast furnaces. Other materials are also classified as by-products, like blast furnace slag, blast furnace gas and so on; Properties of the products are used to classify them as non-energy products and energy products. Non-energy products mainly refer to various types of steel, light burnt dolomite, and part of the sinter, while energy products refer to the output of energy for iron and steel enterprises, basically coke and various types of power.

2.2 Accounting Model Structure. The enterprise model structure is shown in figure 2.Scope 1 refers to the direct emissions of the enterprise, mainly calculating carbon emissions from external input materials processing, and the burning of fuels in the enterprise internal production process. Scope 2 refers to the emissions from purchased power, mainly calculating carbon emissions from the consumption of purchased electricity, steam, and other power. The emissions of scope 3 contain upstream phases, external transport, and output products. Upstream phases calculate indirect carbon emissions from the consumption of purchased raw materials, purchased auxiliary materials, and purchased energy (except for electricity and steam). External transport calculates emissions from consumption of purchased raw materials, purchased auxiliary materials and purchased energy in the transport process. The outputs calculate the carbon content of the credit for non-energy products, energy products, and by-products, as well as the carbon credit for the output of energy. 


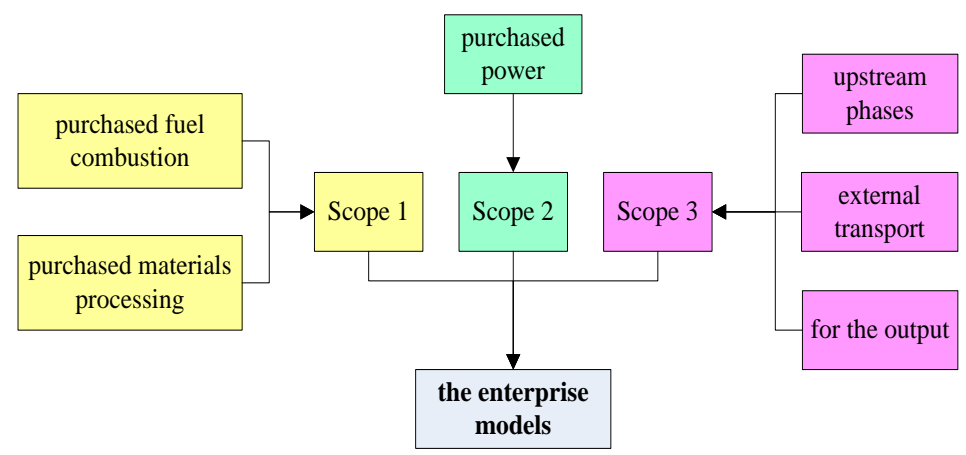

Figure 2. Enterprise model structure.

2.3 Model Accounting Methods. Carbon emissions results mentioned in Section 2.1.2 are obtained by multiplying activity factor level data and its corresponding coefficient of $\mathrm{CO}_{2}$ emissions. The basic formula of the enterprise model according to the principle of the carbon balance is shown as the following:

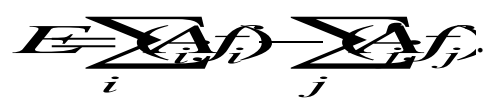

Where $E$ is the total $\mathrm{CO}_{2}$ emissions of enterprise model $(\mathrm{kg}), A$ is the activity factor level data in the input of enterprise model $\left(\mathrm{kg}, \mathrm{m}^{3}, \mathrm{kwh}, \mathrm{km}\right), A^{\prime}$ is the activity factor level data in the output of enterprise model $\left(\mathrm{kg}, \mathrm{m}^{3}\right), f$ is the $\mathrm{CO}_{2}$ emission coefficient of the various activities factor $(\mathrm{kg} / \mathrm{kg}$, $\left.\mathrm{kg} / \mathrm{m}^{3}, \mathrm{~kg} / \mathrm{kwh}, \mathrm{kg} / \mathrm{kg} \cdot \mathrm{km}\right), i$ is the type of activity factor in the input, and $j$ is the type of activity factor in the output.

It can be seen that the model results are directly dependent on the data source and its quality, with activity factor level data provided by companies, and the $\mathrm{CO}_{2}$ emission coefficient obtained by measuring, upstream enterprises and the related database access provided.

\section{Process Model of Integrated Iron and Steel Enterprises}

3.1 Classification of Carbon Emissions Inventory. The enterprise model inputs contain purchased materials and energy outside, the outputs contain the products and by-products and the accounting process does not require internal information of logistics and energy flow. But the process model does require this data, so the process model is more complicated than the enterprise model.

According to the features of the processes of integrated iron and steel enterprises, the processes are divided into the main processes and energy processes, where energy processes provide the enterprise with electricity, coke, steam and water, oxygen and other energy mediums. There is no relationship between the up process and down process. The main processes are the processes of iron and steel smelting with the obvious relationship between the up process and down process.

The classification of inputs and outputs for the process model's carbon sources are shown in figure 3. Inputs include the self-produced products. Steel production belongs to the process industry, where the processes of products become the raw materials of the next procedure. These types of products are called the intermediate products. There are also by-products created through recycling within the enterprise. Hence the intermediate products and by-products are classified as selfproduced products. In addition, integrated iron and steel enterprises have their own energy sector to assist in production, so energy products are also classified as self-produced products. For outputs, the process model can effectively identify the products of each process, therefore the functional products of the main processes are defined as main products, the functional products of the energy processes are defined as energy products, and other non-functional products are defined as byproducts. 


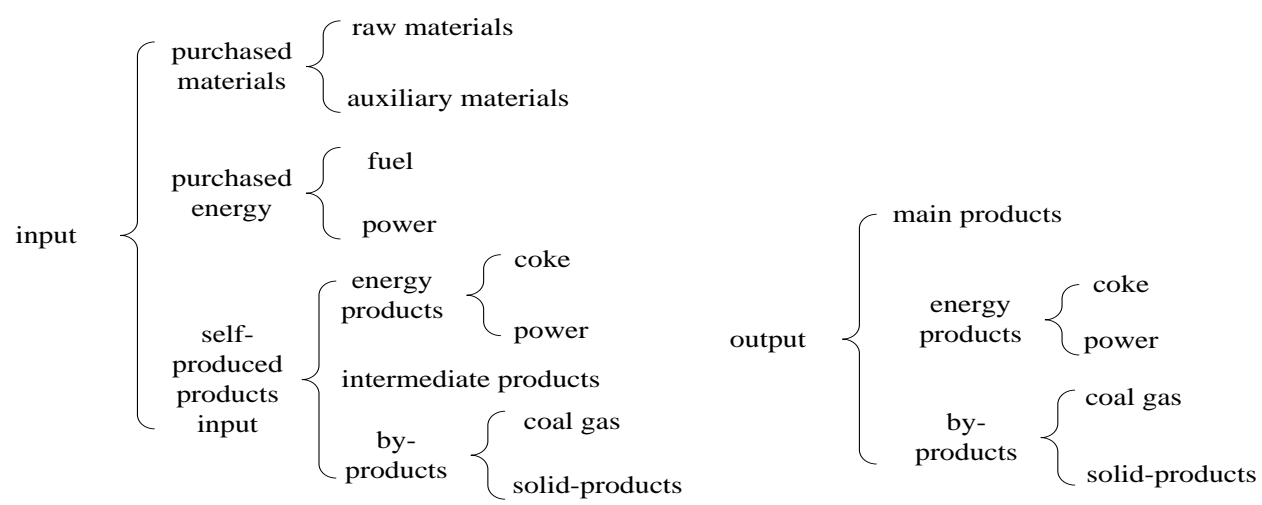

Figure 3. The classification of input and output for the process model's carbon source

3.2 Accounting Model Structure. The process model structure is shown in figure 4. The emissions in scope 1 include purchased fuel combustion, purchased materials processing, self-produced products input, and internal energy output. Purchased fuel combustion and purchased materials processing are used to calculate the carbon emissions from materials processing and fuel combustion during production. Self-produced products input are used to calculate the carbon emissions from the consumption of intermediate products, energy products and by-products. Internal energy output is used to calculate the carbon emissions credit from the energy products and coal gas output. Scope 2 refers to the emissions from the power enterprise purchased, mainly calculated through carbon emissions from the consumption of purchased electricity and steam and other power. The emissions of scope 3 contain upstream phases, external transport, off-site of the energy products and the output products. Upstream phases calculate indirect carbon emissions from the consumption of purchased raw materials, purchased auxiliary materials and purchased fuel. The external transport calculates emissions from consumption of purchased raw materials, purchased auxiliary materials and purchased energy in the transport process. The off-site of the energy products calculates emissions from upstream energy products consumed. The outputs calculate carbon content of the credit for main products and by-products.

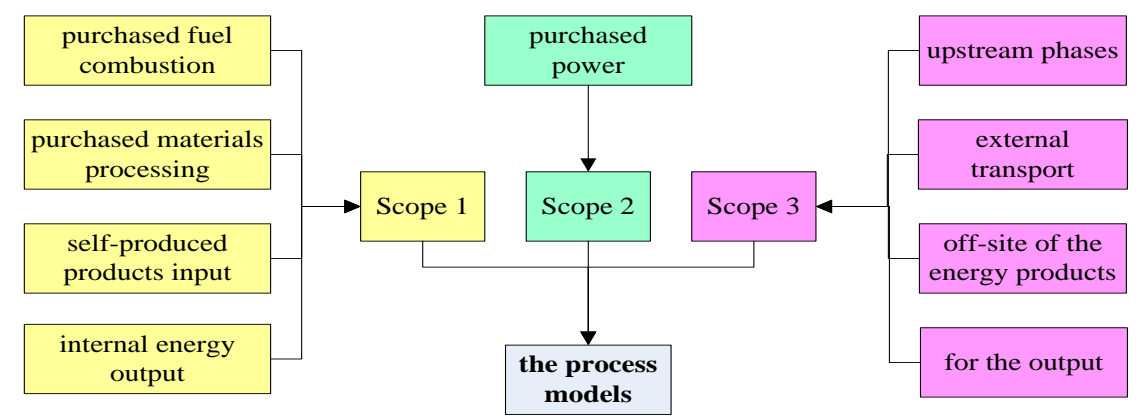

Figure 4. Process model structure

3.3 Model Accounting Methods. The process model needs to consider problems like self-produced products input and internal energy recycling within the enterprise. The basic formula of each process according to the principle of the carbon balance is shown as the following:

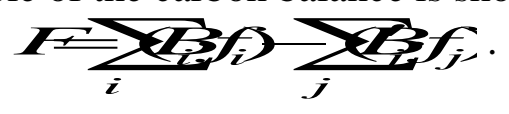

Where $F$ is the total $\mathrm{CO}_{2}$ emissions of process model $(\mathrm{kg}), \mathrm{B}$ is the activity factor level data in the input of process model $\left(\mathrm{kg}, \mathrm{m}^{3}, \mathrm{kwh}, \mathrm{km}\right), B^{\prime}$ is the activity factor level data in the output of process $\operatorname{model}\left(\mathrm{kg}, \mathrm{m}^{3}\right), f$ is the $\mathrm{CO}_{2}$ emission coefficient of the various activities factor $\left(\mathrm{kg} / \mathrm{kg}, \mathrm{kg} / \mathrm{m}^{3}\right.$, $\mathrm{kg} / \mathrm{kwh}, \mathrm{kg} / \mathrm{kg} \cdot \mathrm{km}), i$ is the type of activity factor in the input and $j$ is the type of activity factor in the output.

The inputs of the process model include purchased fuel and materials, the intermediate products, solid by-products, coke, power and coal gas. Coke, power and coal gas belong to the energy selfproduced products. Carbon emissions accounting for these types of products include $\mathrm{CO}_{2}$ emissions 
from fuel combustion, and $\mathrm{CO}_{2}$ emissions from the production phase, as well as the upstream phase. Output of the process model includes main products, energy products, energy by-products and solid by-products. Energy products and energy by-products include the internal energy of the iron and steel enterprises. Carbon emissions credit accounting for these types of products also include $\mathrm{CO}_{2}$ emissions from fuel combustion, and $\mathrm{CO}_{2}$ emissions from the production phase, as well as the upstream phase.

The process model obtains the carbon emissions of each process, which are used to derive the whole carbon emissions of the integrated iron and steel enterprise through addition, as shown :

$$
G=\sum_{l} F_{l} \text {. }
$$

Where $G$ is the total $\mathrm{CO}_{2}$ emissions of all processes $(\mathrm{kg}), l$ is the process number of integrated iron and steel enterprise.

\section{Conclusions}

The following conclusions may be drawn from this study:

(1) The enterprise model includes the whole enterprise in accounting for the enterprise's overall carbon emissions, prompting enterprises to better understand their own status of carbon emissions and the emission reduction potential, and provide data support for energy conservation and emissions reduction with respect to government appraisal of the enterprise. The process model is based on a specific process to account for the process of carbon emissions, so that enterprises can effectively quantify the internal organization's carbon emissions, provide the basis for the internal assessment mechanism of $\mathrm{CO}_{2}$ emissions, and promote internal emission reductions, to achieve the goals of complete enterprise emission reductions.

(2) The enterprise model calculation results found the carbon emissions caused by purchased fuel combustion is the largest, accounting for $89.2 \%$ of the whole enterprise emissions. Among them the purchased coal combustion is the main activity, and accounts for $99.89 \%$. Thus, in order to improve the efficiency of coal-fired enterprises, the purchase of high quality coal, and optimization of the internal coal-fired structure are of great significance for enterprise-wide reduction.

(3) According to the results of the process model, the highest percentage of carbon emissions results from processes using blast furnaces, sinters, coke and converters. Of these, blast furnaces own the largest proportion at $36.3 \%$. In addition, from the point of the integrated iron and steel enterprises process carbon emissions, this also shows the carbon emissions are mainly concentrated in the first half of the complete steel production.

\section{Acknowledgements}

The authors acknowledge gratefully the financial supports from the National Natural Science Foundation of China (Grant No. 41301644) and Research Fund of Anhui University of Technology for Young Teachers (QZ201310).

\section{References}

[1] IPCC. Climate Change 2013: the Physical Science Basis Summary for Policymaker, Switzerland: Intergovernmental Panel on Climate Change,2013.

[2] International Energy Agency: $\mathrm{CO}_{2}$ Emissions From Fuel Combustion Highlights 2013. http://www.iea.org/publications/freepublications/publication/CO2EmissionsFromFuelCombusti onHighlights2013.pdf.

[3] Liu Xiuli et al.. Sub-sector Carbon Dioxide Emissions Estimation That Come from Primal Energy Consumption in China in 2011.Science \& Technology for Development.1, 22-33,2011

[4] IPCC. 2006 IPCC Guidelines for National Greenhouse Gas Inventories[M]， 2007. 
[5] British Standards Institution (BSI). PAS2050:specification for the assessment of the life cycle greenhouse gas emissions of goods and service. British:DEFRA,2008

[6] China National Institute of Standardization.. Corporate greenhouse gas Accounting and Reporting. China Zhijian Publishing House, Beijing, pp.64 76,2011.

[7] WRI and WBCSD.. The Greenhouse Gas Protocol [R], a Corporate Accounting and Reporting Standard Revised Edition.2004

[8] WRI and WBCSD.Sector Toolsets: Iron\&Steel. http:// www.ghgprotocol.org/ calculation -tools/ iron-and-steel-sector. 2008.

[9] International Iron and Steel Institute. Climate Change Emissions Calculation Tool User Guide Version 7.00.2004.

[10] World Steel Association.. $\mathrm{CO}_{2}$ Emissions Data Collection User Guide, Version 6. http://www. worldsteel.org/media-centre/press-releases/2008/data-collection-launch.html.2008.

[11] Posco. Carbon Report[R].Korea: Posco. Nippon Steel.2008. Sustainability Report. Japan: Nippon steel.2009.

[12] Baoshan Iron and Steel Group. 2008 CSR Report of Baoshan Iron and Steel Group Co., Ltd. Baoshan Iron and Steel Group, Shanghai, China. 2008.

[13] World Business Council for Sustainable Development (WBCSD), World Resource Institute (WRI).. The Greenhouse Gas Protocol: A Corporate Accounting and Reporting Standard. Revised Edition. WRI and WBCSD, USA.2004.

[14] Zhang Chunxia et al.. Discussion on GHG Emission Reduction in the Steel Industry. Journal of Engineering Studies. 4(3), 221-230,2012. 